\title{
THE MELTING-POINTS OF SOLID CHLOROFORM, TOLUENE AND ETHER.
}

By E. F. ARChibald AND D. Mcintosh.

Received January 18, 1904.

DURING the course of an extended investigation on the properties of liquefied gases, we found it necessary to construct some low constant temperature baths. After a number of experiments we came to the conclusion that the melting-points of several pure organic substances were extremely satisfactory for our purpose.

Accordingly, we have determined the melting-points of solid chloroform, toluene and ether, with a fair degree of accuracy by means of the hydrogen thermometer, correcting the observed results according to the methods so well worked out by Travers. ${ }^{1}$

Purification of Material.-Two samples of Merck's chloroform were purified by shaking with water and treating with sulphuric acid; each sample distilled steadily at $60.4^{\circ} \mathrm{C}$. under a pressure of $755 \mathrm{~mm}$. of mercury. The toluene used was a sample of Merck's, which had been thoroughly dried with sodium; it distilled between IIO.2 and IIO.6 under a pressure of $765 \mathrm{~mm}$. Ether, which had been standing over sodium for several months, was distilled; it boiled between $34.2^{\circ}$ and $34.7^{\circ}$ under a pressure of $757 \mathrm{~mm}$. A second sample was dried by means of phosphorus pentoxide; it distilled between $34.3^{\circ}$ and $34.6^{\circ}$ under a pressure of $755 \mathrm{~mm}$.

The liquid, whose freezing- or melting-point was to be determined, was poured into a large test-tube, which surrounded the hydrogen thermometer, so as to completely cover the bulb. The liquid was then slowly cooled by means of solid carbon dioxide and ether, or liquid air, being stirred vigorously meanwhile. While the substance was solidifying, the hydrogen thermometer remained practically constant, at least until nearly all the substance had been frozen. The melting-points were determined by surrounding the bulb of the hydrogen thermometer with a pasty mixture of solid and liquid in a vacuum vessel; with vigorous stirring the chloroform and ether melted quite sharply; in the case of the toluene the melting-point did not seem to be sharply defined.

1 Travers: Phil. Trans. Roy. Soc, 200 A., 105. 
Chloroform.-The melting- and freezing-points were identical, namely: $-63.2^{\circ} \mathrm{C}$. This result is probably correct to $0.2^{\circ}$. Berthelot ${ }^{1}$ gives $-70^{\circ} \mathrm{C}$.

Ethor.-The melting-point was found to be $-117.6^{\circ} \mathrm{C}$., which is probably accurate to $0.3^{\circ}$. Olzewski gives $-\mathrm{I} 17.4^{\circ} \mathrm{C}$. Ladenburg and Krïgel ${ }^{3}$ found-II3.I C.

Toluene.-The melting-point varied between $-97^{\circ} \mathrm{C}$, and $-99^{\circ} \mathrm{C}$. Ladenburg and Krügel found $93.2^{\circ} \mathrm{C}$.

A well-stirred mixture of solid carbon dioxide and ether gives a bath having a remarkably constant temperature of about -79.5 C., under normal pressure; by reducing the pressure over this mixture, by means of a good water-pump, constant temperatures down to $-103^{\circ} \mathrm{C}$. can be obtained.

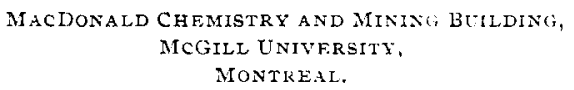

\title{
ON TRISULPHOXYARSENIC ACID.
}

\author{
[PRELIMINaRy Notice]. \\ BY LEROY WILEY MCCAY AND WILLIAM FOSTER, JR \\ Keceived January 29 , roo4.
}

BY THE action of magnesium oxide on freshly prepared arsenic pentasulphide suspended in water, we have obtained a solution from which, after removing the dissolved magnesium with sodium hydroxide, we have been able to isolate the tertiary sodium salt of trisulphoxyarsenic ${ }^{4}$ acid.

We simply add alcohol to the well-cooled solution, then lower the temperature still further, whereupon feathery crystals gradually separate out, which, on standing ${ }^{5}$ in contact with the liquid, pass into fine fern-like forms. By recrystallization in the presence of a small quantity of sodium hydroxide, the salt is obtained pure.

When filtered off, washed with 50 per cent. alcohol and dried

1 Berthelot: Bull. Soc. Chim. [2], 29, 3-4.

2 Olzewski : Wiener Monatsh. Chem., 5, 37.

${ }_{3}$ Ladenburg and Krügel: Ber, d. chem. Ges., 33, 637 .

see the recent work of Foster: Ztschr. anorg. Chem., 37, 64 (1903).

o After adding the alcohol, the flask with its contents is put in the ice-box for about twelve hours. 